\title{
Efeitos de sentido em discursos educacionais contemporâneos: a figura falaciosa da liberdade como promessa de redenção
}

Paula Corrêa Henning

Universidade Federal do Rio Grande

Cleber Gibbon Ratto

Centro Universitário La Salle

\section{Resumo}

Este texto toma a Liberdade, uma das bandeiras da Revolução Francesa, como figuras emblemáticas da episteme moderna que sustenta a produção de um determinado sujeito moral. Para isso, examina alguns fragmentos de teses de doutorado defendidas em 2006 no Programa de Pós-Graduação em Educação da Universidade do Vale do Rio dos Sinos (Unisinos). Com Friedrich Nietzsche e Michel Foucault problematiza o conceito de liberdade, demarcando a guerra como condição de possibilidade para constituição de práticas de liberdade. Interessa-se por mostrar alguns potenciais efeitos desses discursos sobre a educação. Para isso, toma a crítica nietzscheana da liberdade em sua dupla vertente: a liberdade de pensar e a liberdade de querer, ambas inscritas no preconceito fundamental da unidade da consciência. De Foucault serve-se de sua crítica ao Iluminismo com ampla penetração em todo o ideário moderno e fortemente presente na educação. Com sua noção de práticas de liberdade, o artigo problematiza esse emblema moderno como um recurso de pensamento que, longe de funcionar como uma redenção do pensamento ou da vontade, é uma possibilidade diante da construção de nossa vida como obra estética. Com isso, busca evidenciar traços da episteme moderna que, ainda hoje, serve de solo positivo para composição da moral operada pela Educação.

\section{Palavras-chave}

Educação - Episteme moderna - Liberdade. 


\section{Effects of meaning in contemporary educational discourses: the fallacious figure of liberty as promise of redemption}

Paula Corrêa Henning

Universidade Federal do Rio Grande

Cleber Gibbon Ratto

Centro Universitário La Salle

\begin{abstract}
This text takes Liberty, one of the flags of the French Revolution, as an emblematic figure of modern episteme, which gives support to the production of a particular moral subject. For that, it examines parts of doctoral theses presented in 2006 to the Graduate Program in Education Studies of the University of Vale dos Sinos (Unisinos). With Friedrich Nietzsche and Michel Foucault, it problematizes the concept of liberty, establishing war as the condition of possibility for the constitution of practices of freedom. It is concerned with showing some of the potential effects of these discourses upon education, and to such purpose takes the Nietzschean critique of freedom in its twofold character: the freedom to think, and the freedom to wish, both inscribed into the fundamental prejudice of the unity of consciousness. It makes use of Foucault's critique to the Enlightenment with its deep influence on modern ideals, and also firmly present in education. With his notion of practices of freedom, the article problematizes this modern emblem as a thinking resource that, far from functioning as a redemption of thought or will, is a possibility for the construction of our lives as an aesthetic work. With that, it seeks to reveal aspects of the modern episteme that, to this day, serve as the ground for the composition of the moral operated by education.
\end{abstract}

\section{Keywords}

Education - Modern episteme - Liberty. 
Liberdade, Igualdade e Fraternidade são emblemas da Revolução Francesa que se tornaram fortes traços da Modernidade. Um acontecimento que, sendo produto dos ideais Iluministas, marca a história do Ocidente, traçando princípios universais na busca do bem para coletividade. Neste texto, estimulados por Nietzsche, pretendemos evidenciar que a luta revolucionária do século XVIII anulou o combate, as relações de força, silenciando alguns a favor do bem universal.

Entendendo que o propósito de trazer ideais modernos em nome do povo foi um dos grandes objetivos da Revolução Francesa, Nietzsche (2001) vai mostrando em seus escritos o quanto posicionamos o homem num lugar de destaque, como aquele que busca o bem para a coletividade. "Foi apenas a Revolução Francesa que pôs o cetro, de maneira total e solene, nas mãos do "homem bom”' (p. 244, grifo do autor).

Como o próprio filósofo nos mostra em seus ensinamentos sobre a prática de guerra, somente podemos guerrear com causas vencedoras. E não há dúvida de que a Revolução Francesa foi uma causa vencedora. Por isso, instigados com o pensamento do filósofo, travamos um duelo de combate com uma dessas figuras de Modernidade, a Liberdade, como um dos emblemas da episteme ${ }^{1}$ moderna, evidenciando os discursos e seus efeitos no campo da Educação na atualidade.

Para isso, apropriamo-nos de teses de doutorado defendidas em 2006 no Programa de Pós-Graduação em Educação da Universidade do Vale do Rio dos Sinos (Unisinos) e utilizamonos de seus ditos para compor o corpus discursivo dessa investigação. Organizamos este estudo na tentativa de evidenciar efeitos de sentido provocados por alguns discursos da Educação na atualidade, que se consolidam em discursos das teses analisadas.

Com discursos emblemáticos de Liberdade, algumas das teses analisadas anunciam a autonomia e a emancipação dos sujeitos como um ideário esperado do projeto educacional moderno. Com ditos recorrentes sobre a busca pela formação do sujeito livre, pretendemos neste texto problematizar os efeitos de sentido que vêm constituindo lemas falaciosos - no dizer de Nietzsche (2005) - prometendo uma redenção aos sujeitos.

Para isso, tomaremos a crítica nietzscheana da liberdade em sua dupla vertente: a liberdade de pensar e a liberdade de querer. Para o filósofo, ambas inscrevem-se no preconceito fundamental da unidade da consciência. De Foucault vamos nos servir de sua crítica ao Iluminismo, com ampla penetração em todo o ideário moderno e da noção de práticas de liberdade, como um recurso de pensamento que, longe de funcionar como uma redenção do pensamento ou da vontade, é uma possibilidade diante da construção de nossa vida como obra estética.

Não pretendemos com a figura emblemática da liberdade fazer uma crítica que apenas julgue essa episteme como problemática ou como um solo a ser abandonado ou substituído. 0 que queremos fazer aqui

não é outra coisa que [nos] inscrever nessa tradição fabulosa, não com o fim de criticar as fábulas da liberdade, mas com o objetivo de continuar fabulando a liberdade criticamente. (Larrosa, 2004, p. 204)

Na esteira dos princípios de prática de guerra, julgamos que nossa escolha é suficientemente ética, na medida em que estamos elegendo um contendor à altura. A figura que vimos colocando sob suspeita é uma figura largamente vitoriosa e é exatamente por isso que nos interessa discutir sua ampla produtividade discursiva, especialmente no campo da educação.

Iniciamos a problematização do assunto a partir de um acontecimento ímpar na ordem do saber: o século das Luzes. A constituição do que somos hoje, sujeitos livres, determinou-se fortemente pelo conceito de liberdade presente

1. A partir de Foucault (2002a e 2002b) estamos entendendo episteme como uma ordem intrínseca que nos faz pensar, ser e agir de determinada forma, ordenando os saberes a partir da condição de possibilidade dada pela episteme daquele momento histórico. Assim, ela ordena e valida os discursos criando o campo das possibilidades e impossibilidades de nossas vontades de saber. 
no cenário Iluminista, tendo Kant como sua principal matriz. Buscando nas Luzes uma saída para o estado de menoridade do homem, Kant sustenta o entendimento de que por meio da razão, da consciência e do esclarecimento o homem se libertará de uma condição menor. Uma condição que nos exige passividade em aceitar a determinação de outros em guiar o nosso uso da razão.

Como é obrigação do próprio homem sair dessa condição de menoridade, ele deve criar possibilidades para a operacionalização desse processo. Assim, são necessárias coragem e audácia pelo saber. E essa maioridade é adquirida quando o homem obedece às regras/ normas sociais para então poder raciocinar. Com isso, Kant evidencia que temos a liberdade da consciência na medida em que exercermos uma espécie de obediência social. Com esse preceito, Kant nos mostra que não há uso livre da razão, mas um uso governado pelas regras/normas impostas pela sociedade.

A liberdade não é, sem dúvida, um tema inaugurado com a Modernidade ou com Kant, mas nos interessa aqui a expressão que ela assumiu nesse momento histórico do pensamento. Trata-se, aqui, da liberdade do homem. Antes disso, ainda, da possibilidade de uso da liberdade pela razão humana. Da naturalidade da consciência e do fato inquestionável da liberdade humana, deduz-se uma transcendência e uma filosofia correlata.

\section{[...] A transcendência da pessoa origina-se do fato de ela ser consciente e livre. (Tese 1, 2006, p. 219)}

A consciência esclarecida faz do sujeito um ser livre, uma condição de vida que somente a partir do uso racional é possivel usufruir. Com essas condições, Kant cria uma teorização de liberdade que faz funcionar o grande projeto do século XVIII: o Iluminismo. Para tanto, é necessária a Educação, levando o indivíduo a esclarecer-se, segundo os princípios sociais, devendo segui-los para alcançar sua maioridade. Esse projeto de pelo menos três séculos parece ainda estar presente na contemporaneidade, talvez com outras roupagens, mas ainda encarnado nas práticas discursivas, como é o caso do excerto citado acima. Neste texto, buscamos problematizar tal projeto, intentando compreender os discursos de liberdade anunciados nos textos de algumas teses.

Além disso, outra razão para essa escolha por circunstanciar a crítica da liberdade refere-se ao recorrente aparecimento de formas discursivas em que é possível reconhecer traços bastante nítidos dos princípios da educação prática ou moral defendidos por Kant. Embora não haja referência explícita ao autor, ou à tradição filosófica nos materiais analisados, é importante reconhecer que essa é a matriz conceitual que alimenta o pensamento educacional moderno e que, mesmo sem clareza disso, assume tais princípios como sua cartilha de operação.

Resumindo, estamos tomando a liberdade a partir da expressão que ela assume no pensamento moderno, onde é tratada como a emancipação e a autonomia do sujeito, resultados esperados do adequado exercício da razão esclarecida.

Foucault (2005), problematizando o acontecimento das Luzes convence-se de que mesmo com sua proposta, o Iluminismo não nos tornou maiores. De todo modo, é a partir dele que a liberdade, como conhecemos e professamos hoje, toma a forma de uma figura emblemática que se pretende universal e possibilitadora de uma consciência esclarecida. Aliás, vale pontuar que a razão à qual me refiro aqui é a razão fundamentalmente moderna, a razão esclarecida, que tem como pressuposto fundamental a soberania da consciência humana sobre todas as outras possíveis formas de racionalidade.

Para consolidação desse projeto, a Modernidade produziu um conjunto de elementos que engendraram a tentativa da libertação pela consciência.

Esse conjunto inclui elementos de transformações sociais, tipos de instituições políticas, formas de saber, projetos de racionalização dos conhecimentos e das práticas, mutações tecnológicas, que são muito difíceis de re- 
sumir em uma palavra, embora muitos dos fenômenos sejam ainda importantes no momento atual. (p. 346)

Um desses elementos é possível dizer que foi a Educação prática ou moral de Kant (2002). Esse projeto visava à construção do homem para viver como ser livre.

A educação prática ou moral (chama-se prático tudo o que se refere à liberdade) é aquela que diz respeito à construção (cultura) do homem, para que possa viver como um ser livre. Esta última é a educação que tem em vista a personalidade, educação de um ser livre, o qual pode bastar-se a si mesmo, constituir-se membro da sociedade e ter por si mesmo um valor intrínseco. (p. 34)

Para essa formação é necessária uma relação direta entre educação e moral, já que essa ética somente pode ser fundada pela razão, e essa fundação é tarefa da ação educativa. Não sendo algo inato do homem, deve existir a Educação para colocar em operação aquela condição indispensável para compreensão, interiorização e execução da moral: a razão consciente.

A Educação toma um lugar de destaque no pensamento kantiano para a emancipação do sujeito, para o progresso da moral e, consequentemente, para a libertação da humanidade da ignorância e, acima de tudo, para a consolidação de nossa maioridade.

Nos termos que conhecemos a Educação hoje, ou seja, institucionalizada, laica e de responsabilidade do Estado, nasce um espaço de transposição das justificações religiosas da ética para as justificações racionais modernas, das quais Kant apresenta-se como principal emblema. Vale destacar que não apenas Kant, mas toda uma tradição filosófica iluminista tem na emancipação do homem sua maior pretensão.

Tal reflexão gerou teorias filosóficas que, a despeito das diferenças, tinham como ideia central que o homem pode evoluir de um es- tado de imaturidade para a maturidade, de heteronomia para a autonomia, chegar ao mais alto nível de desenvolvimento moral e tornar-se livre e emancipado, porque racional. O Iluminismo (Aufklärung) pretendeu um processo de autodeterminação consciente que atingiria sua plenitude na história da humanidade, através do qual o homem conduziria livremente seu próprio destino. Emancipação não é slogan, mas o tema histórico do Iluminismo (Aufklärung). (Hermann, 2005, p. 21)

No entanto, esse projeto universalista de Kant e a sua consequente tradição pedagógica não alcançaram os fins a que se propunham. Talvez menos por desconsiderar a diversidade do mundo em sua complexidade e mais por assumir categoricamente a crença na universalidade do bem e na boa vontade do homem para alcançá-lo. A Educação, na tentativa de produzir esse conhecimento moral e internalizá-lo nos sujeitos, a partir de uma razão esclarecida, pautou seu trabalho especialmente numa Educação prática ou moral que resulta pouco viável.

0 mundo já não é mais o mesmo do século XVIII, e a busca por uma ética universal de fundamento unicamente racional parece ser um projeto inviável na atualidade. Pensar na Educação como instituição que garante a maioridade do homem além de ser uma utopia peca também por desconsiderar outras potências da Educação como geradora de práticas de liberdade não universais. Ou seja, uma proposta que nos coloque a pensar sobre a moral naturalizada e talvez nos possibilite a construção de uma nova ética.

Isso nos leva na direção de perceber um forte contraste presente nos discursos das teses em face de seus potenciais efeitos. De um lado, a apologia das diferenças, das idiossincrasias, das singularidades, enfim, um panorama multifacetado. De outro, a defesa de valores redentores que foram gerados a partir de um projeto universalista e nada atento a tais diversidades.

Ao entender a Educação prática ou moral de Kant, percebemos o quanto, com roupagens 
diferentes, alguns discursos das teses sob análise são tomados por esse grande e insidioso projeto de libertação, mesmo que trabalhem com um mundo cada vez mais distante daquele sonhado por Kant. Pensando sobre as aproximações possíveis entre esse projeto kantiano de libertação das consciências pela razão esclarecida, na busca da maioridade do homem e os discursos atuais sobre liberdade, selecionamos um fragmento da Tese 2 que nos parece exemplar:

A educação é toda a ação consciente ou não de condução de desenvolvimento que o ser humano exerce sobre si e sobre os outros, a fim de formar-se a si e aos outros seres como humanos está, assim, implicado no que os seres humanos podem ir se tornando, em como podem ir aprendendo e decidindo sobre suas vidas. A esta educação como um vir a ser que tem a ver com os processos de aprender, de realizar, de transformar, e, de conduzir intencionalmente ou não, as pessoas na produção de sua humanidade evidencia-se nos DSCs [Discursos dos Sujeitos Coletivos] algumas ideias que expressam a noção desse grupo profissional de formação como aprendizagens, conscientização e mudança. (Tese 1, 2006, p. 263, grifos nossos)

Com pretensão universal de libertar a todos os sujeitos das cadeias de opressão, os discursos educacionais, de um modo geral, assumam eles feições mais técnico-científicas, críticas ou humanistas, consolidam-se por bases modernas de uma Educação que, à semelhança do projeto kantiano, busca a produção da virtude. Querendo formar o homem virtuoso, os discursos educacionais contemporâneos lutam pela maioridade da razão que constituiria o homem como sujeito capaz de dominar a si, aos outros e ao mundo em que vive ou, então, capaz de "ir aprendendo e decidindo sobre suas vidas”. A razão continua a ser, assim como em Kant, a condição fundamental para produção da liberdade do homem, tornando-se possível somente a partir de uma conscientização de si e do mundo.
Com isso, a Educação torna-se um espaço em que civilizar, moralizar e humanizar são as ações esperadas para que a luta pela liberdade seja possível. Para essa produção, a política do disciplinamento dos sujeitos é fundamental. Docilizando e utilizando os corpos é possível recompensar por meio da promessa da redenção numa vida racional, livre, emancipada e por decorrência feliz. Não está aí, nesse discurso contemporâneo, a pretensa formação educacional de libertar o sujeito da sua menoridade (Kant, 2002)?

Se a produção do humano exige o disciplinamento de corpos e almas, a recompensa vem na forma da promessa de salvação pelo acesso a uma experiência plena, racional, livre e emancipada, em uma sociedade humanizada e moralizada, justa e igualitária. (Garcia, 2002, p. 45)

A frase de Maria Manuela Garcia lembra-me fortemente de outra muito conhecida de Foucault (2002c) entendendo que a liberdade se constitui ao mesmo tempo em que se constituem as disciplinas ${ }^{2}$. A liberdade, como uma invenção moderna, teve como condição de possibilidade para sua gestação as disciplinas. Por isso, a liberdade professada pelos ideários modernos da Revolução Francesa, é falaciosa. Não se liberta alguém senão por um processo de sujeição pelo trabalho disciplinar e normalizador. Nesse sentido, a liberdade que hoje podemos visualizar não funciona como uma liberdade redentora e emancipadora, mas como uma liberdade que, paradoxalmente, ao mesmo tempo que possibilita práticas de resistência, também regula nossas ações. E é nesse sentido que a promessa de uma liberdade irrestrita é tida como falaciosa por Nietzsche (2000): como ser livre quando existem certas ações, práticas e morais a serem seguidas para que, a partir disso, possamos ser homens livres?

Os homens foram pensados "livres", para que pudessem ser julgados e punidos - para que

2. A frase a que nos referimos é a bem conhecida escrita em Vigiar e punir: "as Luzes que descobriram as liberdades inventaram também as disciplinas" (Foucault, 2002c, p. 183). 
pudessem ser culpados. Consequentemente, toda ação precisaria ser considerada como desejada, a origem de toda ação como estando situada na consciência. (p. 49)

Queremos defender a ideia de que, apesar de alguns discursos das teses criticarem a hegemonia dos discursos modernos, muitos estão alicerçados nos ideários dessa mesma episteme. E, aqui, especialmente tratando da liberdade, a proposta de Kant se efetiva: a Educação como fundamento para o exercício da razão esclarecida, almejando a autonomia e a superação da menoridade do homem.

Entendemos que esses discursos colocam a liberdade na ordem do verdadeiro, constituindo e produzindo fortes efeitos de sentido em nossas vidas. A Educação liberta é uma verdade tão indiscutível quanto enraizada no solo da episteme moderna. Porque conhecer, nessa perspectiva, é sinônimo de tomar consciência e libertar-se, é tomar consciência de si próprio como sujeito da razão.

Com uma proposta de formar para a liberdade, a Educação crê formar para o bem. Há algo de errado nisso? Não! A escola moderna foi organizada para atender a esse projeto. Entretanto, se entendemos o regime de produção desse discurso e a instalação da liberdade na ordem do verdadeiro, por força de uma política discursiva específica, já não se pode concordar tranquilamente com a inevitabilidade e a hegemonia indiscutivel de tal ordem. 0 bem também precisa ser discutido. A aceitação tácita de que a liberdade é a verdade natural do humano faz com que a moral seja jogada num plano transcendente que, por consequência, a torna indiscutivel.

Reiterando o que vimos problematizando neste texto, queremos reforçar que o Projeto Oficial da Modernidade, especialmente com Kant, alicerçou-se nos ideários de progresso pela razão e consciência, na formação de um sujeito livre, autônomo e emancipado. A Educação vem a contribuir, de forma decisiva, para a concretização desse projeto. 0 campo educacional proclama um discurso de liber- tação e conscientização que, não sem razão, aparecem recorrentemente em algumas das teses analisadas.

\section{[...] educar nada mais é do que humanizar,} caminhar para emancipação, autonomia responsável, a subjetividade, a moral e a ética. [Arroyo, 1998, p. 144]

Para Nietzsche (2004), a educação como “a empreitada de formar o ser humano mais humano nunca foi tarefa fácil” (p. 48). É um ato tenso porque trata de formar o sujeito livre, entendendo a liberdade como fazendo parte da conduta humana (Tese 2, 2006, p. 263, grifos nossos).

A noção de conscientização nos toma, fazendo-nos crer que é preciso sair dessa consciência ingênua, ou dessas trevas em que não pensamos, para uma consciência crítica, racional, autocentrada. Os ideários iluministas invadem nossa forma de fazer Educação, acreditando ser imprescindível trazer a luz para que possamos compreender claramente os processos de exclusão, impedindo que eles se proliferem, tornando o mundo mais justo e fraterno, com uma missão redentora da Educação que conscientiza, cura e liberta os sujeitos de sua menoridade intelectual e moral. "De fato, como poderíamos tornar os homens felizes, se não os tornarmos morais e sábios?" (Kant, 2002, p. 28).

A Educação, por sua vez, constitui-se como a mais eficaz das tecnologias para efetivar essa passagem sonhada pelo Iluminismo, do conhecimento à moral. A Educação seria a ponte que tornaria possível o progresso humano que conecta a consciência ao conhecimento e o conhecimento à moralidade; isso nos faria felizes. A Educação opera permanentemente com esse misto de uma liberdade natural inquestionável que nos faz potentes para pensar e querer como sujeitos unitários e autônomos, potenciais dominadores de todas as outras forças do mundo.

Nesse solo positivo, a moral, como anunciou Kant, tornou-se um projeto social. A relação que o sujeito moderno estabelece com um conjunto de valores produz-se como verdade, 
sendo atravessada por um sentimento de dever colocar tais princípios em ação. Por moral estamos entendendo "um conjunto de valores e regras de ação propostas aos indivíduos e aos grupos por intermédio de aparelhos prescritivos diversos, como pode ser a família, as instituições educativas, as Igrejas etc." (Foucault, 2006, p. 26). A moral como um conjunto de regras coercitivas, julgando ações e produzindo valores como certo e errado, bem e mal. Nesse sentido, entendo que a proposta educacional vem permeada por esse conjunto de valores a que se refere Foucault.

0 que percebemos em tal função emancipadora da Educação é a tentativa de colocar em funcionamento esses modos de ação, capturando os sujeitos numa malha de valores pré-estabelecidos pela moral moderna. Não me parece haver aqui um ser autônomo e consciente de suas ações, mas um sujeito que, capturado por essa moralidade, assume seus atos como se fossem seus originalmente.

Essas problematizações me remeteram ao pensamento de Nietzsche (2004). Até que ponto ao querermos ser livres e lutarmos para isso não estamos nos tornando presas de nós mesmos? Não estamos lutando por libertarmonos de situações aprisionistas e, na medida em que conseguimos, não nos tornamos dominados por nossas ações? Ou então, nas palavras do próprio filósofo:

Independência (chamada liberdade de expressão em sua dose mais fraca) é a forma de renúncia que o ansioso por domínio adota finalmente - ele, que longamente procurou o que pudesse dominar, e nada encontrou senão a si mesmo. (p.169, grifo do autor)

Por isso, ao pensar em Liberdade como emblema do mundo, por que não pensarmos nela como um discurso falacioso, já que ao querer libertar-se terminamos por ser presas de nós mesmos ou então por criar uma liberdade que ao mesmo tempo em que liberta de algumas situações - e acreditamos nisso! - acaba por produzir também, e paradoxalmente, condições de regulação?

0 domínio de si é uma maneira de ser homem em relação a si próprio, isto é, comandar o que deve ser comandado, obrigar à obediência o que não é capaz de se dirigir por si só, impor os princípios da razão ao que desses princípios é desprovido; em suma, é uma maneira de ser ativo em relação ao que, por natureza, é passivo e que deve permanecê-lo. (Foucault, 2006, p. 75)

Tanto na relação com o pensamento, quanto com a vontade, o preconceito moderno fundamental, apontado por Nietzsche, é o da unidade da consciência. 0 sujeito que pensa ou quer livremente, é, antes de tudo, um sujeito consciente e idêntico a ele mesmo, unitário.

Nietzsche, ao propor uma crítica à razão lógica de Descartes, ensina-nos que a liberdade do pensar nada mais é do que uma falácia inventada pela ilusão de sermos dotados de uma unidade da consciência. Estremecendo as bases sólidas de uma hipótese cartesiana, o filósofo anuncia que a unidade racional do Eu não existe. A liberdade de pensamento deriva da ilusão de que por categorias lógico-racionais compreendêssemos o que é mesmo o mundo, construindo uma interpretação transcendental e global do mundo. Para Nietzsche, essa interpretação deriva de observações de processos que nós mesmos constituímos.

Além disso, o eu penso é também uma falácia, por acreditar que comandamos nosso pensar. Entretanto, segundo o filósofo:

um pensamento vem quando 'ele' quer e não quando 'eu' quero, de modo que é um falseamento da realidade efetiva dizer: o sujeito 'eu' é a condição do predicado 'penso'. (Nietzsche, 2005, p. 21, grifos do autor)

Com isso, não é possível entender o ato de pensar como um ato livre; na verdade o pensar é o resultado de impulsos forçosamente 
incitando-nos a pensar. Acreditar que pensamos e agimos quando queremos é uma falácia, pois o ato de liberdade de pensamento é um dos tantos mitos inventados pela Modernidade, na tentativa de nos garantir uma posição melhor neste mundo. Talvez o que possamos pensar são pequenas ações de liberdade, mas sempre a partir de um complexo e não garantido domínio de nós mesmos, como diria Nietzsche.

Governando-se o homem alcança a liberdade. A liberdade aqui entendida como um processo que por práticas pontuais e isoladas torna possível, eventualmente, a composição de outras possibilidades de existência. Por isso, quando tratamos de liberdade estamos entendendo, a partir de Foucault, sujeitos livres como aqueles

sujeitos individuais ou coletivos que têm diante de si um campo de possibilidade onde diversas condutas, diversas reações e diversos modos de comportamento podem acontecer. (Foucault, 1995, p. 244)

Nossas opções e escolhas não são questões privadas, são, pelo contrário, escolhas governadas por esse conjunto de valores que nos cerca e direciona nosso olhar para o que convencionamos chamar de certo, bem, verdadeiro. Pensar e querer não partem de uma origem primeira dada na intimidade do sujeito. Assim como o pensamento, a vontade também não é ditada pela liberdade humana, mas por um conjunto de condições que nos fazem desejar, escolher e decidir moralmente.

Indagando sobre a suposta certeza de nossa liberdade de querer, Nietzsche (2005) busca dissolver a proposição tão conhecida por nós: o eu quero. A vontade é entendida, aqui, não como escolhas individuais e unitárias, mas como um complexo jogo de forças que põe em funcionamento o sentimento, o pensamento e o afeto. Para Nietzsche somos tocados, movidos por nossos sentimentos e pensamentos. Por uma disposição de ânimo, por um afeto de comandar, a vontade obedece a trama de forças que constitui o querer. Assim, a liberdade de querer nada mais é do que a obediência aos seus sentimentos e pensamentos. Uma obediência mobilizada pelo afeto de comando, fazendo com que o sujeito domine a si mesmo. Daí por que se acredita ser um sujeito livre.

Liberdade de querer, nessa perspectiva, assume uma proposição falaciosa na medida em que esta somente ocorre quando aquele que quer comanda-se a fazer determinada ação e a executa. Entretanto, essa vontade que o mobiliza à ação não parte do sujeito falante, mas, antes, de uma estrutura social de muitas almas (Nietzsche, 2005), ou seja, o querer parte da doutrina moral que faz com que tenhamos vontade de algumas coisas e não de outras. Assim, o próprio querer, que é o fundamento para a liberdade, é colocado sob suspeita aqui: o eu quero acaba por ser efeito da relação de forças que se trava nos preceitos morais instituídos pela sociedade. Com isso, não há domínio de seu próprio querer, já que esse querer não parte do próprio sujeito, mas é resultado de um governo da coletividade.

A vontade, nesse sentido, a partir de um afeto de comando, busca incessantemente a soberania do Eu. Uma tentativa frustrada do sujeito que, ao procurar sua liberdade de querer, depara-se com um domínio de si e um irresistível afeto de comando. Uma vontade que vem governada por tantas almas que acaba por incorporar valores, ideais e formas de ser e viver não inerentes à unidade da consciência do $\mathrm{Eu}$, mas imanentes ao próprio mundo que constitui morais e preceitos a serem seguidos, como se estes fossem escolhas nossas, como se fossem tão soberanos ao ponto de conseguir, enfim, uma liberdade no ato de pensar e no ato de querer.

0 que é querer - Rimos daquele que saiu de seu aposento no minuto em que o Sol deixa o dele, e diz: "Eu quero que o Sol se ponha"; e daquele que não pode parar uma roda e diz: "Eu quero que ela rode"; e daquele que no ringue de luta é derrubado, e diz: "Estou aqui deitado, mas eu quero estar aqui deitado!”. No 
momento, apesar de toda risada, agimos de maneira diferente desses três, quando usamos a expressão "eu quero"? (Nietzsche, 2004, p. 95)

Com essas provocações de Nietzsche pensamos que, por meio de discursos pedagógicos morais, o sujeito vai compondo sua vida encharcada de valores políticos, sociais, culturais, regulando suas ações com o que é e o que não é permitido dentro dessas regras de convivência na busca da harmonia social. Os diferentes discursos que nos capturam - pedagógicos, culturais, médicos, psicológicos etc. - nos incitam a agir, ser e estar no mundo regulando nossos corpos e almas por meio de critérios previamente estabelecidos pela episteme vigente.

0 discurso pedagógico moral torna-se uma estratégia de controle, onde outras coisas, além dos conteúdos ensinados pela escola, podem e devem ser aprendidas pelos escolares. Uma ordem moral que se efetua não apenas na escola, mas nos diferentes espaços sociais por onde os sujeitos irão passar. Essas aprendizagens dizem respeito à sua formação como um agente moral, considerando a moralidade não uma questão de valores ou princípios, mas muito mais que isso: uma questão de obrigação (Larossa, 1999).

A educação procede quase sempre assim: ela procura encaminhar o indivíduo por uma série de estímulos e vantagens, para uma maneira de pensar e agir que, quando se torna hábito, impulso e paixão, vigora nele e acima dele, de encontro a sua derradeira vantagem, mas para o bem de todos. (Nietzsche, 2001, p. 71, grifos do autor)

Todos os discursos modernos anunciados e problematizados neste texto vieram compondo muitos dos ditos das teses analisadas neste estudo, conciliando certa coerência dentro da ordem discursiva em que se inscrevem.

0 que percebemos é que os discursos modernos, por excelência, conseguem, de modo muito particular, produzir efeitos de sentido concretos nas práticas cotidianas da Educação, sejam eles por meio de métodos e técnicas de como ensinar, sejam por meio do emblema da formação crítica e esclarecida das consciências. Nas teses que se associam fortemente aos valores modernos, a efetividade desse discurso sobre as práticas educativas parece clara, funcionando com uma proposta lógica para formação docente e para o currículo escolar.

Apesar de nossa crítica aos principais efeitos de tamanha efetividade desses discursos no campo educacional, é evidente que são eles os que, de maneira mais eficaz, dão conta de produzir uma educação que serve aos interesses da coletividade como ela vinha sendo pensada até então.

Percebendo essa efetividade dos emblemas modernos na educação, começamos a pensar que regimes de efetividade são possíveis a partir de discursos como os produzidos neste texto que faz a crítica da hegemonia moderna e dos efeitos por ela produzidos há pelo menos três séculos. Pensamos nisso por perceber que os discursos modernos, questionados ou não, produzem efeitos diretos na prática do professorado. Os efeitos óbvios de uma Educação justificada pelos ideais modernos é a condução da formação dos professores na direção de práticas que garantam a efetivação da própria promessa da Modernidade, ou seja, a ilustração, a autonomia, o progresso e a ordem.

0 que nos colocamos a pensar é que, nesse mesmo solo positivo da episteme moderna, é possível criar rachaduras que nos levem a pensar sobre os emblemas modernos do mundo e, por conseguinte, da Educação escolarizada. Talvez alguns efeitos possíveis do referencial que assumo neste estudo, sejam decorrentes do desafıo de assumir essa tensão, e não negá-la, com tudo que ela tem de difícil, complexo, trabalhoso e ao mesmo tempo potente. Nisso acreditamos que residam as práticas de liberdade tratadas por Foucault $(2004 ; 2006)$. Práticas que nos levem na direção de pensar o pensamento, de constituir outras possibilidades de olhar a Educação e produzir nossas práticas docentes. 
Rachando com muitos dos ideais modernos que nos constituem, porém, sem a ilusão de imunidade ante esse forte ideário.

Acreditamos ser importante pensar num movimento que nos leve a criar outras formas de estar no mundo, outras formas de pensar a Educação. "Essas ordens não são talvez as únicas possíveis nem as melhores" (Foucault, 2002b, p. XVI) e a partir desse entendimento é possível pensar: podemos inventar nossas próprias ordens, produzindo enfim outros olhares, contudo, sem a ilusão de que nos libertamos defınitivamente de todas as heranças da Modernidade. Essa ordem, esses valores modernos que criticamos são os mesmos dos quais fizemos parte. Porém, é possível pensarmos em pequenas revoltas todos os dias, para compor novas formas de ser e viver o contemporâneo. A isso, Foucault chamou de práticas de liberdade.

Trabalhando com o conceito de práticas de si, Foucault evidencia que estas operam na autoformação do sujeito como "um exercício de si sobre si mesmo através do qual se procura se elaborar, se transformar e atingir um certo modo de ser" (Foucault, 2004, p. 265). Com isso, as práticas de si podem nos levar às práticas de liberdade, já que a partir delas podemos revisitar nossa vida e constituí-la com outras formas de viver, para além de uma moral para sempre válida.

Entretanto, não queremos dizer que as práticas de si são inventadas unicamente pelo sujeito que as vive, mas sim que elas são possíveis, a partir de sua própria cultura. De qualquer forma, é presumível pensar sobre elas e compor outras formas de vida, com esquemas já organizados dentro do próprio mundo em que se vive.

A busca de uma nova ética por meio de uma luta política se efetiva quando tentamos diminuir os efeitos de dominação de uns sobre os outros, fazendo com que as estratégias para a guerra possam ser colocadas em funcionamento, como relações de poder para um combate justo.

Pensamos que o exercício de práticas de liberdade somente se torna possível em espaços de guerra ou, como diria Nietzsche (2000), somente é livre o guerreiro. Falamos de uma liberdade que possibilita a ação sobre a ação dos outros, uma liberdade como "algo que se tem e não se tem, que se quer, que se conquista..." (p. 96). E por essa conquista que é, paradoxalmente, também uma perda, precisamos lutar cotidianamente pelo seu retorno, o que somente é possível para homens que se fazem fortes, que travam lutas e estruturam um campo de ação sobre suas possibilidades de resistir aos efeitos de dominação. A essas lutas identificamos aqui o conceito de guerra em Nietzsche e Foucault. Uma guerra que nos leve na direção de travar batalhas contra o assujeitamento. Ao tratar de lutas que se efetivam pelas ações sobre ações dos outros, entendemos a guerra como condição de possibilidade de agir sobre os sujeitos livres.

“A guerra é a mãe de todas as coisas boas" (Nietzsche, 2001, p. 118). Pensando nesse sentido, é possível perceber os efeitos da guerra como possibilidades de criação e práticas desviantes, que nos levem na direção de lutar pela liberdade, mas longe de entendê-la como redenção para um mundo melhor. Propomos pensar uma liberdade que nos desafie ao exercício de elaboração de nós mesmos.

[...] se a questão kantiana era saber a que limites o conhecimento deve renunciar a transpor, parece-me que, atualmente, a questão crítica deve ser revertida em uma questão positiva: no que nos é apresentado como universal, necessário, obrigatório, qual é a parte do que é singular, contingente e fruto das imposições arbitrárias. Trata-se, em suma, de transformar a crítica exercida sob forma de limitação necessária em uma crítica prática sob a forma de ultrapassagem possível. (Foucault, 2005, p. 347)

Uma ultrapassagem que seja possível. Talvez mais modesta, sem a preocupação pelo alcance à maioridade, mas uma diminuição dos efeitos de dominação que sofremos cotidianamente. Possibilitar práticas desviantes e criativas de ser e agir na nossa produção ética, sem 
desconhecer ou recusar a tensão permanente que nos coloca em luta com o que vínhamos sendo. Novas maneiras de pensar a Educação; novos meios para o exercício da criatividade e da liberdade, todos eles gerados na luta entre o que deveríamos ter nos tornado e o que efetivamente acabamos nos tornando.

Repensando o conceito de liberdade em Kant, no corpus discursivo desta pesquisa e nos confrontos entre conceitos como os de Nietzsche e Foucault, pensamos que é um desafıo compor a educação cotidianamente com práticas desviantes. Práticas com possibilidades de intervenção, possibilidades que coloquem os escolares e nós, como profissionais da Educação, a pensar o pensamento e, quem sabe, resistir e criar outras estratégias de pensar a Educação.

Que ninguém mais seja responsável, que o modo de ser não possa ser reconduzido a uma causa prima, que o mundo não seja uma unidade nem enquanto mundo sensível, nem enquanto espírito: só isso é a grande libertação. (Nietzsche, 2000, p. 50, grifos do autor)

Vendo o mundo como uma constituição produzida por nós mesmos em tensão com as contingências, não acreditamos que exista uma moral ou ética autêntica. E exatamente por isso é possível pensarmos na nossa vida como uma criação ininterrupta.

Com essa perspectiva, chamada por Foucault de estética da existência e não uma ética moral, a liberdade resulta de pensar sobre a própria vida e produzi-la como uma obra de arte, produzi-la por práticas de liberdade possíveis. Assim, a liberdade aqui não é vista como um fundamento racional e uma condição natural possível a partir da razão esclarecida. A liberdade é vista como resultado da produção de uma ética. A isso, Nietzsche chamou de espírito livre. Certamente, fazer de nossa vida uma obra de arte não é tarefa fácil. Entretanto, o convite para a criação de uma nova ética é instigante, na medida que, em o aceitando, somos jogados a dançar na beira do abismo...

Quando uma pessoa chega à convicção fundamental de que tem de ser comandada, torna-se crente; inversamente, pode-se imaginar um prazer e força na autodeterminação, uma $l i$ berdade da vontade, em que um espírito se despede de toda crença, todo desejo de certeza, treinado que é em se equilibrar sobre tênues cordas e possibilidades e em dançar até mesmo à beira de abismos. Um tal espírito seria 0 espirito livre por excelência. (Nietzsche, 2001, p. 241, grifos do autor)

Equilibrar-se em cordas bambas, fazer de nossa vida uma obra de arte e resistir a efeitos de dominação e sujeição a uma moral instituída se configuram como jogos cada vez mais abertos, atraentes e fascinantes, tanto quanto difíceis, trabalhosos e complexos. Por isso, somente é possivel práticas de liberdade com práticas de guerra, constituindo a vida num permanente jogo de ganho e perda pela liberdade, numa permanente dança à beira de abismos. 


\section{Referēncias bibliográficas}

FOUCAULT, M. História da sexualidade, 2: 0 uso dos prazeres. 11. ed. Rio de Janeiro: Graal, 2006. 2005.

Ditos e escritos II: arqueologia das ciências e história dos sistemas de pensamento. Rio de Janeiro: Forense Universitária,

Ditos e escritos V: ética, sexualidade e política. Rio de Janeiro: Forense Universitária, 2004.

A arqueologia do saber. 6. ed. Rio de Janeiro: Forense Universitária, 2002a.

As palavras e as coisas: uma arqueologia das ciências humanas. 8. ed. São Paulo: Martins Fontes, 2002b.

Vigiar e punir: nascimento da prisão. 25. ed. Petrópolis: Vozes, 2002c.

O sujeito e o poder. In: DREYFUS, H.; RABINOW, P. Michel Foucault: uma trajetória filosófica: para além do estruturalismo e da hermenêutica. Rio de Janeiro: Forense Universitária, 1995. (Apêndice da $2^{a}$ edição. Michel Foucault entrevistado por Hubert Dreyfus e Paul Rabinow).

GARCIA, M. M. A. Pedagogia crítica e subjetivação. Petrópolis: Vozes, 2002.

HERMANN, N. Ética e estética: a relação quase esquecida. Porto Alegre: EDIPUCRS, 2005.

KANT, I. Sobre a pedagogia. 3. ed. Piracicaba: Editora Unimep, 2002.

LARROSA, J. Linguagem e educação depois de Babel. Belo Horizonte: Autêntica, 2004.

. A construção pedagógica do sujeito moral. In: SILVA, T. T. da (Org.). Liberdades reguladas: a pedagogia construtivista e outras formas de governo do eu. Petrópolis: Vozes, 1999.

NIETZSCHE, F. Além do bem e do mal: prelúdio a uma filosofia do futuro. São Paulo: Companhia das Letras, 2005.

Aurora: reflexões sobre os preconceitos morais. São Paulo: Companhia das Letras, 2004.

A gaia ciência. São Paulo: Companhia das Letras, 2001

Crepúsculo dos ídolos, ou como filosofar com o martelo. Rio de Janeiro: Relume Dumará, 2000.

Recebido em 24.07.09

Aprovado em 15.02 .10

Paula Corrêa Henning é doutora e mestre em Educação pela UNISINOS/RS e UFPel/RS e graduada em Pedagogia. Atualmente é pesquisadora e professora adjunta da Universidade Federal do Rio Grande - FURG (Rio Grande/RS). Professora permanente dos Programas de Pós-Graduação Educação em Ciências e Educação Ambiental. Membro do Grupo de Pesquisa no CNPq "Cultura, Subjetividade e Políticas de Formação".

Cleber Gibbon Ratto é doutor em Educação pela PUC/RS e graduado em Psicologia. Atualmente é pesquisador e professor do Programa de Pós-Graduação em Educação do Centro Universitário La Salle - UNILASALLE. Membro do Grupo de Pesquisa no CNPQ “Cultura, Subjetividade e Políticas de Formação". E-mail: cleber.ratto@unilasalle.edu.br. 